\title{
POLÍTICAS E CONCEPÇÕES DE FORMAÇÃO: IMPACTOS NO TRABALHO DO PROFESSOR
}

\author{
TRAINING POLICIES AND CONCEPTIONS: IMPACTS ON THE TEACHER'S WORK
}

Jocélia Barbosa Nogueira ${ }^{1}$

Universidade Federal do Amazonas - UFAM

\begin{abstract}
Resumo
O artigo ancorado no método qualitativo pretende desenvolver uma análise sobre as concepções de formação do pedagogo no mundo contemporâneo, os dilemas de ser professor e desenvolver o trabalho pedagógico, sob um currículo centrado na pedagogia das competências e na pedagogia dos resultados, habilitando o agir docente a partir do modelo de educação decorrente de influências do Banco Mundial, que estabelece critérios de avaliação da escola centrada na política da "premiação". No contexto das políticas de formação de professores, o pedagogo enfrenta desafios no mundo do trabalho, movido pelas tensões do ofício de ensinar e pelas exigências da reforma educacional. Historicamente, o ajuste estrutural da década de 1990 no governo de Fernando Henrique Cardoso privatizou a nação, desmontou a face social do Estado, ocasionando a privatização em todos os segmentos sociais, pois modificou as estruturas estatais e, inevitavelmente, modificou os movimentos sociais, desmantelou os sindicatos, permitiu a inserção de instituições de modelos desenvolvimentistas em parceria com o Estado neoliberal. Tal projeto ortodoxo, de caráter monetarista, centrou seus objetivos na ampliação do Estado capitalista e reduziu o indivíduo aos interesses do mercado. A educação que hoje vivenciamos está distante do alcance dos objetivos do direito social subjetivo.
\end{abstract}

Palavras-chave: Educação; Trabalho; Políticas Públicas; Formação de Professores.

\begin{abstract}
The article anchored in the qualitative method intends to develop an analysis on the conceptions of pedagogue formation in the contemporary world, on the dilemma of being a teacher and having to develop the pedagogical work under a curriculum centered on the pedagogy of competences and on the pedagogy of results, enabling a teaching action based on the influence model of the World Bank, which establishes school evaluation criteria centered on "award" policies. In the context of teacher education policies, the pedagogue faces challenges in the world of work, driven by the tensions of the teaching profession and the demands of the educational reform. Historically, the structural adjustment of the 1990s under the government of Fernando Henrique Cardoso privatized
\end{abstract}

\footnotetext{
${ }^{1}$ Professora Doutora do Departamento de Administração e Planejamento do Curso de Pedagogia da Faculdade de Educação da Universidade Federal do Amazonas - UFAM. - E-mail: jocelia.bnogueira@hotmail.com.
} 
the nation, dismantled the social face of the state, causing privatization in all social segments, as it modified state structures and, inevitably, modified social movements, dismantled the unions, allowed the insertion of institutions of developmental models in partnership with the neoliberal State. This orthodox project, of a monetarist nature, focused its objectives on the expansion of the capitalist state and reduced the individual to the interests of the market. The education we are experiencing today is far from reaching the goals of subjective social law.

Keywords: Education; Job; Public policy; Teacher training.

\section{INTRODUÇÃO}

Em primeira instância discorreremos sobre as políticas de formação de professores, de maneira geral, da década de 1990 quando da reforma do Estado e, posteriormente, explicitaremos a nova configuração do trabalho docente, analisando fatores que levaram ao desgaste profissional da categoria de pedagogos movidos pelas políticas públicas de formação nas escolas.

Em função de uma frágil formação, o pedagogo tem a profissão precarizada e a falta de identidade profissional materializada pelo amplo raio de ação no âmbito das instituições escolares e não escolares acarreta o convívio com baixa-estima social provocada pela desvalorização salarial.

Em uma sociedade que prioriza os valores capitalistas em detrimento dos valores de uma formação humana e omnilateral, a lógica que prevalece é a que se rende à lógica do capitalista. Nesse sentido, para este profissional o conhecimento se plasma no trabalho em mais valia, incorporando uma lógica tecnicista de um professor tarefeiro e alienado que não reflete sobre sua práxis.

A âncora teórica desse estudo, de método bibliográfico, será na área de políticas públicas de formação do pedagogo, sendo assim elegemos Aquino (2012), por tratar da crise da educação formal no fulgor dos processos de governamentalização educacional; Brzezinski (2012), por apresentar a análise da política nacional de formação do pedagogo a partir das Diretrizes Curriculares Nacionais do curso de graduação em Pedagogia; Freitas (2012), pois discute o impacto da lógica empresarial na organização escolar; Frigotto (2011), por apresentar os circuitos da história e o balanço da educação no Brasil na primeira década do século XXI; Evangelista (2010) traz à discussão as políticas públicas educacionais contemporâneas, analisando a formação docente e os impactos na escola; e, por último, Oliveira (2012), por apresentar as políticas de formação e desenvolvimento profissional docente. 


\section{EFEITOS DA REFORMA DO ESTADO NAS POLÍTICAS DE FORMAÇÃO DOCENTE: MODELOS DO AJUSTE ESTRUTURAL DA DÉCADA DE 1990}

A reforma de 1990, segundo Freitas (2012), modificou drasticamente o setor educacional e ganhou nova face com a adoção de modelos curriculares cartesianos, centrado na lógica financista e empresarial, onde a educação é vista como rentável e oferecida como um 'fetiche' de mercadoria. Estas premissas mercadológicas deram nova 'performatividade' e regularam as políticas de formação do pedagogo, incidindo drasticamente no trabalho docente, em todos os níveis de ensino.

O trabalho do professor no contexto desta reforma apontou exigências que o lançaram a uma atitude desafiadora: dar conta da multiplicidade de modalidades educativas e mediar saberes da profissão, aliada à precarização do trabalho e de formação, impulsionando desenvolver seu ofício diante das complexidades do mundo contemporâneo.

As reformas educacionais da década de 1990 causaram impactos negativos ao desembocarem abruptamente nas escolas, contrariando a trajetória docente, disseminando o desânimo de professores, fato percebido de modo sintomático por meio da insatisfação profissional, em que os efeitos das políticas do governo de Fernando Henrique Cardoso e, posteriormente, do governo Lula da Silva, modificaram drasticamente os rumos do trabalho docente em função da reestruturação produtiva que altera as relações sociais de produção e agrega ao trabalho docente a tarefa de formar um novo tipo de homem para uma nova sociedade de consumo, plasmada na lógica do capital.

Aliada à crise do capital, a escola pública experimenta um colapso de amplas proporções. O alvo não se restringe à Educação Básica, mas, também, ao Ensino Superior. Nesse sentido, a partir da Lei de Diretrizes e Bases da Educação Nacional (LDBEN) n 9394/1996, a formação do pedagogo centrou o foco na docência da educação infantil e anos iniciais do ensino fundamental. Para tanto, a formação desse profissional da educação deve possuir intencionalidade pedagógica instituída de receituários provindos do Referencial Curricular Nacional para a Educação Infantil (BRASIL, 2002), além de outros documentos como os Parâmetros Curriculares Nacionais (BRASIL, 1997), que legitimam técnicas procedimentais de ensino alheios à experiência cultural do professor, conferindo-lhe nova rotina em sala de aula e nova rota de trabalho com a criança. 
Os impactos de uma formação centrada na reforma do Estado mostram interesses corporativos empresariais, orientada na "Pedagogia das competências" e na "Pedagogia dos Resultados" embasada na concepção de "qualidade total", e confirma que o interesse do Estado é manter acordo com os empresários para fortalecer o capital, conforme os ditames do lucro e da mais-valia. Assim, vemos a escola se tornar palco de programas como Plano de Desenvolvimento da Escola - PDE, entre outros, que fortalecem a lógica do mercado.

Para Saviani (2011) o PDE é o carro chefe do Índice de Desenvolvimento da Educação Básica (IDEB), instituído com a finalidade de indicar a qualidade da Educação Básica foi produzido pelo Instituto Nacional de Estudos e Pesquisas Educacionais Anízio Teixeira (INEP), atende à lógica de mercado e acepção filosófica financista contida no referido documento, demonstrando que o PDE é um acordo de Estado e empresários. Segundo Frigotto (2010, p. 45) "[...] revela a um tempo o caráter cínico do movimento e a disputa ativa pela hegemonia do pensamento mercantil no seio das escolas públicas", que influenciou e ainda influencia as políticas públicas de formação do pedagogo, elucidando um contexto de disputas.

O primeiro ponto de atenção está na fragmentação das políticas públicas de ações focais que não dão conta das reais necessidades da educação e acabam se tornando ações esvaziadas de uma pedagogia. Este cenário de reformas desenha na matriz de formação do pedagogo desafios que representam o novo agendamento da prática docente ou mesmo, proporciona o esvaziamento do trabalho escolar e dá ênfase na burocratização do ensino e do currículo.

O segundo ponto diz respeito aos processos de avaliação de resultados balizados pelo produtivismo e, por último, a base da "pedagogia das competências" e a "pedagogia dos resultados" vêm regendo a filosofia da política educacional no Brasil. Nesse sentido,

[...] o Estado em vez de alargar o fundo público na perspectiva do atendimento a políticas públicas de caráter universal, fragmenta as ações em políticas focais que amenizam os efeitos, sem alterar substancialmente as suas determinações. E, dentro dessa lógica, é dada ênfase aos processos de avaliação de resultados balizados pelo produtivismo e à sua filosofia mercantil, em nome do qual os processos pedagógicos são desenvolvidos mediante a pedagogia das competências (FRIGOTTO, 2010, p.245).

Para contextualizar melhor, exemplificamos 0 acordo do Estado com os empresários no processo de formação no Brasil e percebermos como é imperioso reconhecer a necessidade da criação de cursos de Licenciatura para formar professores 
de educação infantil, no caso de Licenciatura em Pedagogia, e, das séries iniciais do ensino fundamental. Contudo, o que vem acontecendo é que as instituições são constituídas de consórcios e oferecem cursos em todas as regiões do país, registrando-se uma ampla e desordenada difusão das licenciaturas à distância e a desmensurada ampliação de vagas, sem as devidas condições de atendimento para acompanhar e supervisionar estes cursos; acarretando incertezas no campo da formação das diversas modalidades oferecidas. Tal situação atinge todo o Sistema de Ensino que, atrelado ao mercado, passa a tratar da educação como uma relação de negócio.

Para Frigotto (2010) existem três mecanismos em ampla expansão nesse processo de consolidar a educação às relações de mercado. Todavia, a título de memória histórica no Brasil, a educação sempre esteve no campo da acirrada disputa hegemônica do capital. $\mathrm{O}$ autor enfatiza que

A educação, quando apreendida no plano das determinações e relações sociais e, portanto, ela mesma constituída e constituinte dessas relações, apresenta-se historicamente como um campo de disputa hegemônica. Esta disputa dá-se na perspectiva de articular as concepções, a organização dos processos e dos conteúdos educativos na escola e, mais amplamente, nas diferentes esferas da vida social, aos interesses de classe (FRIGOTTO, 2000, p.25).

Assim, o primeiro mecanismo articulador das concepções e práticas educacionais mercantis, característica da década de 1990, era transmitir a ideia das parcerias entre o público e o privado face à ineficiência da escola pública, e o segundo mecanismo procura

[...] atacar a natureza da formação docente realizada nas universidades públicas, com o argumento de que os cursos de Pedagogia e de licenciatura se ocupam muito com a teoria e com análises econômicas sociais inúteis e não ensina o professor as técnicas do "bem ensinar" (FRIGOTTO, 2011 p. 248).

Centrada nas "pedagogias dos resultados", obedecendo à lógica do mercado e celebrando os rituais de uma pedagogia produtivista proclamada por uma formação construída pelo adestramento profissional, centram-se as políticas de formação de professores ancoradas na estratégia da concepção neoliberal do Estado Mínimo, regido pela ampla reforma do Estado e adequação de planos e programas, objetivando enquadrar custos em educação às exigências de qualidade.

O que se deseja, pelo contrário, é a escola democrática, de acesso universal e includente, onde os processos avaliativos representem esforço no campo da aquisição do conhecimento ideal para transformar a realidade, assim, "[...] o conhecimento humano em seu conjunto integra-se na dupla e infinita tarefa do homem de transformar a natureza 
exterior e sua própria natureza" (VASQUEZ, 2011, p.226). A política de formação de professores deve preparar para transformar a realidade e para isso deve advir dos componentes de formação humana e estão intimamente ligadas às políticas públicas atreladas à educação.

\section{POLÍTICAS PÚBLICAS DE FORMAÇÃO DO PEDAGOGO: DOCENTE, PESQUISADOR E GESTOR}

Segundo Brzezinski (2012), as Diretrizes Curriculares Nacionais do Curso de Pedagogia (DCN-Pedagogia-2006), arcabouço legal de políticas sobre os cursos de formação de professores para a educação básica e a cultura educacional de formação de professores, se cercam de mecanismos que podem direcionar as tendências na política nacional de formação do pedagogo. A autora parte do pressuposto:

[...] de que as DCN-Pedagogia (2006), tanto quanto o arcabouço legal de políticas sobre o curso de formação de professores para a educação básica e a cultura educacional de formação de professores, compõe um conjunto de mecanismos que podem induzir as tendências de uma política nacional de formação de pedagogo (BRZEZINSKI, 2012, p.375).

Para Brzezinski (2012), com a implementação nas instituições formadoras das orientações prescritas nas DCN-Pedagogia-2006, a nova configuração diz respeito à identidade do profissional de pedagogia que sofreu um 'redesenho' e, em face da ampliação do campo de ação deste profissional, deve atuar como docente, pesquisador e gestor.

Os documentos que encaminharam a reorientação curricular expressa nas Diretrizes Nacionais para o Curso de Pedagogia, além de apresentarem um desafio posto em articular as atuais políticas públicas de formação do pedagogo com o mundo do trabalho, focam em outro desafio no campo de atuação deste profissional em função da precarização das condições de trabalho pela desvalorização salarial, desprestígio social e exigências de um Estado regulador de políticas neoliberais.

O Plano Nacional de Educação (PNE), o Plano Estadual de Educação (PEE), o Plano de Desenvolvimento da Educação (PDE), o Programa Mais Educação (PME), o Programa Dinheiro Direto na Escola (PDDE), entre outros gerados pelo Governo Federal e os acordos com a política neoliberal do Banco Mundial no campo da reforma da educação são ajustes comprometidos com o crescimento econômico e representam um processo de luta ideológica, que nos tempos em que vivemos desgastou-se por não considerar outros fatores que implicam no processo de formação de pedagogo para 0 
mundo contemporâneo, sendo pertinente compreender que tipo de formação consubstanciará a práxis deste profissional de ampla atuação no campo da educação?

Os embates e tensões presentes na nova configuração deste profissional ainda são na esfera ideológica das relações com o Estado Mínimo, regulador e avaliador que imprime políticas e dispositivos legais no campo da educação que, expressos nas tendências de formação, divergem de concepções epistemológicas sobre a pedagogia como ciência e as concepções de educação, de formação do pedagogo, de base comum de formação, de docência. (BRZEZINSKI, 2012)

A reformulação do curso de Pedagogia como parte do processo global de reestruturação do Estado, cujas bases estão nas reformas educacionais da década de 1990, incidiu fortemente nas formas de construção da experiência/identidade do educador, assim como a configuração de sua identidade/subjetividade.

A formação do pedagogo, a partir das políticas de reformulação do curso de Pedagogia traçadas pelo MEC, não consubstancia este profissional a produzir conhecimento para intervir na formação de um novo tipo de homem, os modelos de programas da reforma curricular fortaleceram a concepção de um pedagogo pragmático e tecnicista.

Os caminhos de caráter mercantil reduzem a subjetividade humana e fragilizam suas vidas, coisificam os sujeitos às relações capitalistas, nesse contexto Frigotto (2010, p. 251) assevera que:

Para o mercado não há sociedade, há indivíduos em competição. E para o mundo da acumulação flexível, não há lugar para todos, só para os considerados mais competentes, o que passam pelo metro que mede o tempo fugaz da mercadoria e de sua realização. As consequências disso são mais que visíveis em vários aspectos. Nossos cursos tornam-se cada vez mais elitistas. Nele percebo um duplo processo de mutilação e atrofiamento de capacidades intelectuais. Por outro lado, os jovens doutores, para atuarem na pós-graduação têm crivos cada vez mais refinados de ingresso. Por outro, os pesquisadores não resistem a essa pressão ou se recusam a se enquadrar nessa lógica, não sem humilhação, ou saem ou são convidados a sair. O fundamental para muitos pró-reitores e programas de pós-graduação e atingir o máximo de pontos da escala de 1 a 7 , mesmo que saibamos que a lógica dos indicadores se funda na visão positivista e funcionalista do conhecimento e que, de antemão, se saiba que há um efeito trava ou gangorra para que apenas uns fiquem no topo.

A partir dos ajustes do governo às políticas neoliberais regidas pelo Banco Mundial, todas as instituições, contando primeiramente com o Estado, sofrem alterações em função de um processo acelerado no mundo do trabalho, sendo prioridade para o Estado 
o crescimento econômico. Segundo Florestan Fernandes (1992), bem lembrado por Frigotto na Conferência de Abertura da 33aㅗ Reunião Anual da Associação Nacional de Pós-Graduação e Pesquisa em Educação (ANPEd) em outubro de 2010, 'o Brasil não considera ser a educação uma prioridade'. Frigotto anuncia na verve de Florestan que:

A educação nunca foi algo de fundamental no Brasil, e muitos esperavam que isso mudasse com a convocação da Assembleia Nacional Constituinte. Mas a Constituição promulgada em 1988 confirma que a educação é tida como assunto menor, não alterou a situação (FERNANDES, 1992, p. 34).

Para França (2006), as políticas educacionais se sustentam em três grandes prioridades: racionalização organizacional, mudança nos padrões de gestão e a melhoria e qualidade de ensino. Para o Governo Federal e, sucessivamente, para o fortalecimento das parcerias por meio dos acordos com o Banco Mundial, essas prioridades são ações que desenvolvidas no campo da educação podem acionar o crescimento econômico e reduzir o índice de pobreza no país.

No Brasil, a preocupação dos governos com a educação do povo tem apresentado diferentes enfoques na política de formação de professores. Para Evangelista (2012), as políticas educacionais contemporâneas causam impactos da lógica empresarial no trabalho docente. A autora elenca como impactos, a reconversão, a sobrecarga, estreitamento curricular, segregação socioeconômica, precarização da formação, destruição moral do professor e do aluno, destruição do sistema público de ensino e, por último, a ameaça à democracia.

Para Evangelista (2012), a reconversão docente implica na adesão do professor à agenda da reforma educacional, cujo sentido último é dado pelo interesse de manutenção da hegemonia do capital, formando perfil de professores como objetos e, portanto, passíveis de serem reconvertidos. A reconversão à agente da reforma educacional do 'desenvolvimento do Brasil' torna o professor sem autonomia quanto aos objetivos e ao sentido do seu trabalho, professor tarefeiro e alienado.

De acordo com Evangelista (2012), a sobrecarga transforma o professor em superprofessor, enquanto detentor do poder de resolver todos os problemas sociais e econômicos, ampliando o alargamento exponencial das tarefas docentes e de todas as formas de responsabilização que recaem na figura do superprofessor. A autora nos traz a reflexão sobre o encargo do professor de desenvolver o Brasil através de seu trabalho e ao Estado de lançar dezenas de programas de formação no intuito de que basta desembocá-los no interior da escola e tudo está a salvo nas mãos do professor. 
Contudo, defrontamo-nos com o fenômeno de imensa racionalização elaborada para atribuir as mazelas sociais à educação, sobejamente acuada de "má qualidade", cujo responsável seria o professor. Ou seja, para valer as determinações econômicas que estão na origem da produção dos problemas sociais - e também da sua solução - a educação é chamada a explicá-la e, mais, a resolvê-la. A mágica operada permite, discursivamente, atribuir-se ao professor o condão da redenção social seja pela via educacional. Se consultarmos a página do MEC intitulada Seja um professor (BRASIL, s.d.) leremos, sob dois vídeos, a frase "a profissão que pode mudar o país" (EVANGELISTA, 2012, p.43).

Observa-se que atrelado a essa excessiva responsabilidade atribuída à educação para salvar o Brasil, via a complexidade e multiplicidade do trabalho do professor, está a função do Estado regulador que como um aparato social, consolida as reformas educacionais normatizando as instituições públicas, no caso das regras estabelecidas através dos acordos dentro da visão mercantilista. Para Frigotto (2000, p.60-61):

O trabalho, enquanto força de trabalho, passa a constituir-se numa preocupação visceral, de tal sorte que, perseverante, como nos indica Francisco de Oliveira (1990:2), o caráter excludente das relações sociais determina que, nestas circunstâncias, o trabalho lute para manter-se ou para tornar-se mercadoria.

As condições de trabalho numa sociedade capitalista revelam a exclusão e a opressão dos trabalhadores. As políticas de resultados são esperadas para que o processo de acumulação do capital ocorra intensamente e de modo contínuo.

Para Saviani (1992), as instituições estão à falência porque estamos em tempos de barbárie. Somos capazes de conviver com a violência de todos os tipos e não reagimos. Os fatos violentos são de todas as ordens, assim, para esse autor:

A falência das instituições corresponde a um avanço da barbárie. Convivese cotidianamente e sem indignação com a violência expressa em assassinatos, inclusive de crianças, torturas, miséria e fome que afetam milhões de pessoas. (SAVIANI, 1992, p.26)

[...]

É nesse contexto que se circunscreve a decadência da escola pública [...] Aí se fez referência à crise interna que afeta especificamente os processos pedagógicos. Entretanto, o quadro mais amplo da crise social já afeta diretamente as escolas. São constantes as notícias de depredações de escolas, circulação de drogas e atos de violência de tipos variados no interior das escolas públicas de $1^{\circ}$ e $2^{\circ}$ graus. $E$ também aqui não se trata de fenômeno restrito aos países desenvolvidos (SAVIANI, 1992, p.27).

A educação passa a ser a salvação da humanidade e o professor assume a tarefa redentora, contudo esse trabalho não se materializa em função dos valores opostos e da própria mediação das contradições do sistema capitalista. Por isso, numa sociedade capitalista, os problemas são atribuídos pelas condições de sobrevivência em constantes 
riscos que são criados pelo próprio sistema, pois

Com efeito, este parece ser o dilema vivido pela educação pública na conjuntura atual. A cada dia vai ficando evidente que a sociedade capitalista cada vez mais se põe problemas que não é capaz de resolver. A solução desses problemas implica, pois, a transformação das relações sociais vigentes, a construção de uma nova sociedade, o que recoloca em evidência, agora de forma radical, a questão do socialismo, cada vez mais os professores trabalham em uma situação distanciada entre a idealização da profissão e a realidade de trabalho que tende a aumentar em função das complexidades e da multiplicidade de tarefas que são chamados a cumprir na escola (SAVIANI, 1992, p.27).

O alargamento progressivo do raio de ação escolar, a constatação do elenco de incumbências aos profissionais da educação deixa um rastro de vulnerabilidade e efeito desregulador do trabalho docente. Um espírito utilitarista parece pairar sobre as mentalidades pedagógicas.

Em tempo de modernidade há que se refletir sobre essas novas exigências impostas ao trabalho docente e indagar: onde está essa modernidade da escola? Nem todos os professores conseguem se enxergar nessas novas configurações, nessa modernidade. Nesse sentido, pode-se evidenciar nas políticas de formação docente a rota de criação do "novo professor", protagonista da sua própria alienação.

O Estado regula o processo de racionalização implantado pelas exigências das Organizações Multilaterais (OM) que dominam os países da América Latina e Caribe, ditam regras que bem entendidas se traduzem em imposições e são mecanismos de dominação não somente de subordinação do capital, mas, além disso, trata-se de uma subjugação orgânica e que para Evangelista (2012) está articulada, acertada e pactuada aos objetivos do capitalismo-imperialismo e nos processos de governabilidade que vem colocando o Brasil como partícipe de acordos capitalistas com os organismos internacionais.

Observa-se, no Estado Educador, que a formação dos professores é um assunto a ser tratado de acordo com objetivos do Estado, por isso, constata-se que na década de 1990 as reformas estatais foram imbuídas de organizar o seu discurso e ajustá-lo às reformas dentro das premissas do neoliberalismo, onde são enfatizadas práticas educacionais mercantis. Nesse sentido, Frigotto (2010, p. 27) salienta que:

[...] a primeira década do Século XXI, dominantemente, foi marcada pelas práticas educacionais mercantis típicas da década de 1990, seja no controle do conteúdo do conhecimento, seja nos métodos de sua produção ou na socialização, autonomia e organização docentes. 
Para Freitas (2012), o estreitamento curricular centra o foco nos conteúdos cobrados nos exames, possibilitando o clima competitivo entre profissionais; além da pressão sobre o desempenho dos alunos e preparação para os testes, sem espaço aqueles com dificuldade para a aprendizagem e, infelizmente, desembocam em atitudes fraudulentas, por ser impossível acompanhar o processo e deter o controle total, criando um sentimento de impotência e necessidade de sobreviver diante a tantas cobranças: ajudar o aluno ou alterar a nota final? A precarização da formação pelo apostilamento (dependência de materiais didáticos estruturados) e eliminação da qualificação necessária para adequação metodológica, incipiência de conhecimentos da didática como uma ciência ligada à educação, implicando no fazer pedagógico do professor.

Freitas (2012) assevera ainda que a segregação socioeconômica no território escolar ocorre nas escolas especializadas em determinadas "clientelas" no meio estudantil. Segregação socioeconômica dentro da escola importa em classificar as turmas de estudantes que se destacam e outras que fracassam; trazendo para o interior dessas instituições a lógica que integra os princípios "[...] da produção capitalista realizada pelo modelo toyotista [...] concebido do sistema produtor de mercadorias, do processo de criação e valorização do capital" (ANTUNES, 2011, p.39) que selecionam as melhores equipes para desenvolver o trabalho. Para Freitas (2012), configura um cenário de destruição moral do professor e do aluno, pois a concentração gira em torno da média e da divulgação dos resultados do IDEB, ameaçando a democracia e viabilizando a apropriação das escolas públicas pela iniciativa privada. Estudos de Saviani (1983), Frigotto (2010), Freitas (2012), Aquino (2012), Evangelista (2012) revelam que a reforma do Estado no campo educacional traduz estratégias políticas de caráter "monetarista", "financista", e "rentista", trazendo o alargamento progressivo do raio da ação escolar.

\section{POLÍTICAS PÚBLICAS EDUCACIONAIS CONTEMPORÂNEAS: 0 ESFORÇO DO PROFESSOR EM ASSIMILAR AS NOVAS EXIGÊNCIAS DO TRABALHO DOCENTE}

O Ministério da Educação - MEC é o principal órgão disseminador das políticas cujo efeito é o "fetichismo" traduzido pela lógica capitalista que visa transformar conhecimento plasmado no trabalho em mais-valia, incorpora nas políticas essa lógica que valoriza ao produtivismo, agindo assim, pensam que o trabalho do professor prescinde apenas de roteiros técnicos sem que não haja a necessidade de objetivação de formação sólida na base teórica e epistemológica. Nesses casos, pensar e agir assim, o professor está fadado a uma formação que o 
[...] reduz-se a um adestramento e a um atrofiamento das possibilidades de, no âmbito ético-político e socioeconômico, analisar as relações sociais, os processos de poder e de dominação, e, portanto, de perceber a possibilidade de trabalhar na construção de uma sociedade alternativa. No âmbito dos processos de produção do conhecimento científico, crítico e dos processos de ensino e aprendizagem, fica incapacitado de perceber que os mesmos se gestam e se desenvolvem a partir de determinações e mediações diversas no plano histórico, social e cultural. (FRIGOTTO, 1999, p.95).

O Estado neoliberal revela intencionalidade estratégica de formação de jovens para o trabalho e para as funções técnicas de nível médio e superior regidas pelos ditames da agenda bancomundista que se consolida em políticas educacionais consentidas e naturalizadas, revelando uma das faces do metabolismo do capital (FRIGOTO, 2010), concretizando os objetivos da reforma do Estado baseada na reestruturação produtiva. Para tanto, o Estado oferece pacotes de formação e o financiamento de empresas para aplicar as formações dentro do formato do mercado.

Estes tipos de formação oferecida pelos pacotes de reforma do Estado circunscrevem-se como políticas educacionais contemporâneas centradas na visão financista que protagoniza o adestramento do professor tarefeiro, somando à escola uma ampla ação para cumprir com a função de oferecer a qualidade social da educação através de "[...] prerrogativa de uma gama de ações de teor correcional encarregadas de levar a diante uma modernização civilizadora da sociedade”. (AQUINO, 2012, p. 2)

Aquino (2012, p. 2) adverte que estas novas exigências somadas ao nível de impotência que o professor sente em perceber a complexidade de alcançar o objetivo civilizador da sociedade revela

[...] um rastro de vulnerabilidade pode ser atestado entre seus efeitos concretos, redundando num misto paradoxal de exuberância de seus propósitos declarados e de labilidade de sua consecução, esta caracteriza, amiúde, pela queixa recorrente de impotência por seus profissionais, ilhados na contraoferta de respostas fragmentárias e dissonante às demandas que se gestam sem cessar no entorno social. Daí a alegação recorrente de crise da educação formal.

Correlacionado à ampla ação do raio escolar, observa-se que no interior das instituições escolares os tipos de gestão e coordenação pedagógica não atendem às necessidades e desafios da sociedade brasileira na contemporaneidade, pois,

A contemporaneidade, é inegável, tem testemunhado um alargamento progressivo do raio da ação escolar, consubstanciado na multiplicação do rol de incumbências de seus profissionais [...] preparar o alunado, sempre mais e melhor, quer para o exercício ativo da cidadania, quer para o domínio de habilidades e competências específicas, quer ainda para algum 
tipo de qualificação - seja propedêutica, seja profissional - para o ingresso num mundo em franca complexidade, as missões atribuídas à escolarização não ocultam uma ambição ultra reformista da sociedade, expressa numa multidimensionalidade de funções respiratórias ou salvacionistas dos usos e costumes dos segmentos populacionais sob sua guarda - o que abarcaria indistintamente clientela e agentes escolares. (AQUINO, 2012, p.2).

As políticas de ideário neoliberal são incorporadas pelo Estado brasileiro como condição geradora do crescimento econômico da nação. A principal ação do Estado no âmbito da educação é converter o capital humano na melhor maneira pela qual a visão burguesa reduz à prática educacional a um "fator de produção", a uma questão técnica (FRIGOTTO, 1984). Seu objetivo é normatizar as orientações das políticas educacionais da "nova pedagogia da hegemonia", que a reboque destes ditames chegam às escolas regulando o trabalho docente na figura do "Estado Educador".

No campo educacional, o Estado regulador providencia a criação das leis orgânicas como uma consequência das políticas sociais autoritárias construídas paulatinamente desde 1931. O Estado militarizado com o seu modelo de desenvolvimento posto em prática no período de 1964-1978 elaborou a estratégia para sustentar a política que consubstanciou os modelos do autoritarismo mobilizador e, depois, o autoritarismo desmobilizador ou autoritarismo triunfante, porque se materializou em democracia excludente ou democracia restrita. (Saviani, 1983).

Essa linha de tempo onde se tenta rever a fase da implantação da política do Estado militarizado tem relevância importante para a história da educação brasileira, pois para Cunha (1983) corresponde a mudanças significativas no aparelho escolar, principalmente para o ensino superior. Tivemos desde então a política educacional autoritária, desde a queda do Estado Novo, culminando com sucessivas reformas que nunca resolveram as reais necessidades educacionais do Brasil, com o Estado Novo a Reforma de 28 de novembro de 1968 - Lei Federal no 5.540/68 e na Lei de Diretrizes e Bases do Ensino de primeiro e segundo graus - Lei 5.692/71.

Desse modo, compreendemos que se constitui uma necessidade fundamental o estudo das políticas de formação do pedagogo, pois, segundo Brzezinski (2012), os mecanismos de fundamentação de tais políticas podem consolidar-se a partir das Diretrizes Curriculares Nacionais do Curso de Pedagogia (DCN-Pedagogia-2006) e do arcabouço legal das políticas sobre os cursos de formação dos professores, pois estes arcabouços legais se acercam de mecanismos podendo direcionar as tendências na política nacional de formação do pedagogo e o delineamento de sua identidade 
profissional contemporânea.

O período histórico em que vivemos circunscreve políticas educacionais contemporâneas aliadas à lógica financista, por isso "a educação e a formação humana terão como sujeito definidor as necessidades, as demandas do processo de acumulação de capital [...]" (FRIGOTTO, 2000, p.30), justificando os programas de formação do Estado Educador, colaborando com a formação produtivista que emprega uma multiplicidade de ações, encarregada de teor formativo para obter uma modernização civilizadora da sociedade (AQUINO, 2012).

Cabe instigarmo-nos com o gosto de quem deseja construir uma contra ideologia àquela que se contrapõe à servidão mercadológica e indagar: quais os caminhos a serem percorridos para alcançar a superação dessas novas exigências impostas ao trabalho docente? $O$ professor não consegue se enxergar nessas novas configurações desenhadas nas políticas de formação docente, como por exemplo, a rota de criação do "novo professor", protagonista da sua própria alienação.

No sentido etimológico, procuremos a assertiva de Vásquez (2011, p. 221) que nos encoraja a exercer atividade pensada, sendo possível refletir sobre a práxis, a iniciar pelo próprio significado de atividade que:

[...] opõe-se a passividade e sua esfera é a da efetividade, não a do apenas possível. Isso pode nos ajudar a construir um espaço de atividade na sala de aula e em nosso processo de formação aliada ao compromisso de sermos o que fazemos com a oportunidade de atuação para transformar numa atividade humana de caráter consciente de resultado ideal e produto real.

Podemos enveredar pelos caminhos também propostos por Saviani (1983), da curvatura de ato de consciência que nos possibilita atuar e agir como um sujeito ativo, percebendo que não é curvando para o lado convincente da política neoliberal, mas procurando criar mecanismo para exercer a práxis que nos leva à transformação da realidade.

[...] assim como para se endireitar uma vara que se encontra torta não basta colocá-la na posição correta, mas, é necessário curvá-la ao lado oposto, assim também, no embate ideológico não basta anunciar a concepção correta para que os desvios sejam corrigidos; é necessário abalar as certezas, desautorizar o senso comum. (SAVIANI, 1983, p.63).

Saviani (1983) nos ensinou a lição que possibilita o debate para fortalecer os movimentos sociais em defesa do projeto societário antagônico à modernização e ao capitalismo dependente, conforme explicita Frigotto (2010), pois a educação deve 
desconsiderar os princípios da "pedagogia das competências" e da "pedagogia dos resultados", partindo-se do princípio de que o trabalho docente como práxis educativa é oposto aos processos formativos do pedagogo pautado exclusivamente na aquisição de competências, em detrimento do domínio do conhecimento.

\section{CONSIDERAÇÕES FINAIS}

O artigo abordou os efeitos da reforma do Estado nas políticas públicas de formação docente a partir da reforma de 1990, como modelos de ajuste estrutural que modifica drasticamente o setor educacional, porque ganha nova face com a adoção de modelos curriculares cartesianos, centrada na lógica financista e empresarial. O estudo das políticas de formação de professores demonstra que o trabalho de professor no contexto desta reforma é recheado de exigências que o lança a uma atitude desafiadora: buscar compreender a multiplicidade de modalidades educativas e mediar saberes da profissão, conciliando com sintomas da precarização do trabalho e de formação docente e desenvolver seu ofício diante de um cenário educacional de complexidade no mundo contemporâneo.

Com o estudo pode-se afirmar que o professor medeia sua prática e atribui significado ao seu fazer pedagógico (res) significando saberes assimilados na formação inicial e no exercício da prática. O confronto desses saberes acontece ao interagirem-se com as novas orientações da reforma educacional que chegam ao interior das escolas representando verdadeiras odisseias paradoxais aos saberes da profissionalização, constituindo-se em paradigmas adversos que legitimam e naturalizam a desvalorização dos saberes e das práticas consolidadas no fazer e ser docente.

Outro fator que o estudo indica está relacionado ao alargamento progressivo do raio de ação escolar constatado pelo elenco de incumbências aos profissionais da educação. O aumento de responsabilidade atribuída ao professor deixa um rastro de vulnerabilidade e efeito desregulador do trabalho docente, causando mal estar social e psíquico. Um espírito utilitarista parece pairar sobre as mentalidades pedagógicas. A sala de aula, lugar de vivências de aprendizagem, torna-se uma arena de verdadeiro combate. A crise de sala de aula com as vivências dos educandos vem se agregando ao trabalho do professor.

Como construto de análise, o estudo deixa clara a ideia de que os professores convivem hoje na sociedade moderna com situações inusitadas, surgindo interrogações sobre essas novas exigências impostas ao trabalho docente permitindo-nos indagar: onde 
está essa modernidade da escola?

Através dos autores estudados, conclui-se que o professor não consegue se enxergar nessas novas configurações, o que nos leva a crer que a intenção das políticas de formação docente é planejar a criação do "novo professor", fato que colabora para que o docente seja protagonista da sua própria alienação.

Outra evidência a partir dos estudos mostram-nos que o Estado regula processo de racionalização por meio de implementações exigidas pelas Organizações Multilaterais (OM), no comando dos países da América Latina e Caribe, ditam as regras como imposições e mecanismos de dominação e de subordinação de capital, como também, subjugação orgânica articulada, acertada e pactuada aos objetivos do capitalismoimperialismo que nos processos de governabilidade vem colocando o Brasil como partícipe de acordos capitalistas com os organismos internacionais.

O estudo indica que os impactos das políticas de formação de professores centrada na reforma do Estado são de natureza econômica e se consolidam através de pacto com os interesses corporativos empresariais, na lógica do mercado. Essa lógica está centrada nas contínuas e persistentes "pedagogias das competências e dos resultados".

Conclui-se, também, que a fragmentação das políticas públicas em ações focais não corresponde às demandas da educação do nosso país e acabam se tornando esvaziadas de uma pedagogia mais comprometida, cujas concepções de educação estejam ao encontro com a pedagogia histórico-crítica de uma educação unitária e omnilateral.

O outro fato relevante diz respeito aos processos de avaliação de resultado balizado pelo produtivismo e, por último, a base da "pedagogia das competências" e a "pedagogia dos resultados" que está fundamentada a filosofia da política educacional no Brasil, o que impede o alargamento das políticas públicas de caráter universal, fragmentando as ações em políticas focais.

Assim é possível constatar que as políticas neoliberais são adotadas pelo Estado brasileiro como condição geradora de crescimento econômico da nação com fins de converter capital humano a "fator de produção", empenhado em atender os objetivos da "nova pedagogia da hegemonia" que chegam às escolas regulando o trabalho docente na figura do "Estado Educador".

Constata-se 0 fato de que $\circ$ Estado regulador desqualifica 0 trabalho escolar quando planeja mediações produtivas do capital monopolista e indica-nos o estudo que 
reside contradição do trabalho escolar nas reformas que orientam determinada políticas educacionais.

Há preocupação contundente em compreender os meandros do MEC como principal órgão disseminador das políticas públicas de formação de professores que chegam no cenário educacional e transformam o trabalho em mais-valia, porque amplia o raio de ação escolar, idealiza um professor polivalente, protagonista da sua própria alienação, pois centra formação de professores na lógica tecnicista de um professor tarefeiro e alienado não refletindo sobre sua práxis.

A ação do professor não prescinde de roteiros técnicos sem que haja a objetivação de sólida base teórica e epistemológica, pois sem a qual, estaria fadada a uma formação que reduza este ser ao adestramento impossibilitando-o de realizar no âmbito éticopolítico e socioeconômico, as relações sociais e os processos de poder e de dominação, o que inviabilizaria o trabalho de construir uma sociedade alternativa.

Como nos mostra o estudo, ainda que tenhamos o Estado Regulador a controlar o trabalho docente e o Estado neoliberal a inculcar a lógica individualista, competitiva, dando ênfase à "pedagogia das competências" e a "pedagogia dos resultados" nas políticas de formação de professores, consolidando objetivo do projeto desenvolvimentista da lógica financista/mercantilista, podemos, como nos ensina Saviani, curvar a vara para o lado oposto, pois que, no embate ideológico é fundamental, além de enunciar a concepção correta para corrigir o que está dissonante, desautorizar o senso comum e romper com as certezas.

\section{REFERÊNCIAS}

AQUINO, Julio Groppa. Da crise da educação formal ao fulgor dos processos de governamentalizaçao educacional. E-books do XVI ENDIPE. São Paulo: ENDIPE, 2012.

ANTUNES, Ricardo. Adeus ao trabalho? Ensaio sobre as metamorfoses e a centralidade do mundo do trabalho. 15 ed. São Paulo: Cortez, 2011.

BRZEZINSKI, Iria. Política Nacional de Formação de Pedagogos: tendências pós diretrizes Curriculares Nacionais do curso de graduação em Pedagogia. XVI ENDIPE Encontro Nacional de Didática e Prática de Ensino. Campinas: UNICAMP, 2012.

EVANGELISTA, Olinda. Políticas Públicas Educacionais Contemporâneas. Formação Docente e impactos na escola. E-books da XVI ENDIPE. São Paulo:ENDIPE, 2012.

FRANÇA, M.A. Descentralizaçao Financeira e o Fundesscola: o Plano de 
desenvolvimento da escola, o Programa de adequação de prédios escolares e a sua expansão no Rio Grande do Norte. In: NETO, A.C; NASCIMENTO, I.V.; LIMA, R.N. Política Pública da Educação no Brasil. Porto Alegre: Sulina, 2006.

FREITAS, Luiz Carlos de. Os novos reformadores: o impacto da lógica empresarial na organização escolar. E-books do XVI ENDIPE. São Paulo: ENDIPE, 2012.

FRIGOTTO, Gaudêncio. Os circuitos da história e o balanço da educação no Brasil na primeira década do século XXI. Revista Brasileira de Educação. [on-line], jan-abr, 2011. Disponível em:http://www.redalyyc.org/articulo.oa?id= 27518464013 Acesso 12.04.2018.

A formação e a profissionalização do educador. In: SILVA, Tómaz Tadeu; GENTILI, Pablo (orgs.) Escola S.A.: quem ganha e quem perde no mercado educacional do neoliberalismo. Brasília: CNTE, 1999, p.75-105.

Educação e crise do capitalismo real. 4 ed. São Paulo: Cortez, 2000.

A produtividade da escola improdutiva: um (re) exame das relações entre a educação e a estrutura econômico-social e capitalista. São Paulo: Cortez- Autores Associados, 1984. (Coleçao Educação Contemporânea).

OLIVEIRA, Dalila Andrade. Políticas de Formação e Desenvolvimento profissional docente: da intenção às práticas. E-books do XVI ENDIPE. São Paulo: ENDIPE, 2012.

SAVIANI, Demerval, NEOLIBERALISMO OU PÓS-LIBERALISMO? Educação Pública, Crise do Estado e Democracia na América Latina: Estado e Educação. Campinas -SP: Papirus: Cedes: São Paulo: Anped, 1992. (Coletanea C.B.E.)

SAVIANI, Demerval. Educação: do senso comum à consciência filosófica. São Paulo: Cortez, 1983.

VASQUEZ, A.S. Filosofia da Práxis. Rio de Janeiro: Paz e Terra, 2011. 